\title{
ESPAÇO ABERTO \\ O mal-estar na Academia: produtivismo científico, o fetichismo do conhecimento-mercadoria
}

\author{
EUNICE TREIN \\ Universidade Federal Fluminense \\ JOSÉ RODRIGUES \\ Universidade Federal Fluminense
}

A crítica já não necessita de ulterior elucidação do seu objeto, porque jáo entendeu. A crítica já não é fim de si, mas apenas um meio; a indignação é o seu modo essencial de sentimento, e a denúncia a sua principal tarefa.

MARX, 2005

Um mal-estar assombra a Academia: o mal-estar provocado pelo fetiche do conhecimento-mercadoria e o seu canto de sereia - o produtivismo. Professores, pesquisadores e estudantes universitários, e até mesmo os chamados "gestores de Ciência \& Tecnologia”, enfim, a Academia parece estar desagradada e, em alguma medida, degradada pela direção e pelo ritmo do desenvolvimento das transformações em curso no chamado sistema brasileiro de ciência e tecnologia. ${ }^{1}$

Em que pesem os inúmeros depoimentos e estudos que vêm demonstrando os limites desse processo e suas nefastas consequências pessoais, institucionais e científicas, os membros da Academia parecem igualmente convencidos da inevitabilidade dessa marcha forçada ao Desenvolvimento Científico \& Tecnológico e também de suas proclamadas finalidades "sociais".

1 Para efeitos deste texto, denominamos sistema brasileiro de ciência e tecnologia o conjunto de instituições que desenvolvem sistematicamente atividades de pesquisa científica, tais como universidades, centros de pesquisa e as entidades de fomento (fundações estaduais de amparo à pesquisa, Coordenação de Aperfeiçoamento de Pessoal de Nível Superior (CAPES) e Conselho Nacional de Desenvolvimento Científico e Tecnológico (CNPq), além dos Ministérios da Educação e da Ciência e Tecnologia. 
Contudo, não podemos concordar que o prolongamento, sob formas cada vez mais aperfeiçoadas, do atual modo de produção do conhecimento científico conduzirá a sociedade brasileira - enfim - ao télos de uma Economia Competitiva, ${ }^{2}$ pela mão do Desenvolvimento Científico \& Tecnológico. Nesse sentido, é urgente que nos organizemos coletivamente para dissolver os fantasmas que nos assombram.

Para apresentar tais reflexões, organizamos este breve texto ${ }^{3}$ em quatro seções, a saber: 1 . O mal-estar na civilização: forças opostas em luta; 2. O fetichismo do conhecimento-mercadoria: valor de troca e valor de uso na Academia; 3. Mapeando o mal-estar na Academia; e, finalmente, 4. À guisa de conclusão.

\section{O MAL-ESTAR NA CIVILIZAÇÃO: FORÇAS OPOSTAS EM LUTA}

Em meados de 1929, então com 73 anos, Sigmund Freud (1865-1939) concluiu um polêmico e ambicioso livro, considerado por alguns o seu texto mais sombrio: O mal-estar na civilização (Freud, 2006). Curiosamente, antes mesmo de os manuscritos serem entregues à editora, numa terça-feira, 29 de outubro, a Bolsa de Valores de Nova York quebrou, lançando o capitalismo na Grande Depressão (Gay, 1989). Em setembro de 1930, às vésperas da publicação da segunda edição de $O$ mal-estar na civilização, o partido nazista, então com 12 deputados, no Reichstag, logrou eleger 107 parlamentares (Gay, 1989). A tragédia aproximava-se rápido.

Como é sabido, Freud não foi um teórico político, antropólogo ou historiador das religiões, mas o fundador da psicanálise. E, como tal, empregou os recursos de seu pensamento a quase todas as manifestações humanas. De fato, Freud pretendia colocar a própria sociedade burguesa no divã.

2 Sobre a noção de télos, ver Rodrigues (1998).

3 Trabalho encomendado pelo GT Trabalho-Educação (GTTE) e apresentado na 33a Reunião Anual da Associação Nacional de Pós-Graduação e Pesquisa em Educação (ANPEd), Caxambu, outubro de 2010. Cabe informar que uma versão condensada e ligeiramente modificada foi publicada, em fevereiro de 2011, na Universidade e Sociedade, n. 47, sob o título "Crítica do fetichismo do conhecimento-mercadoria", por solicitação da Editoria da Revista do Sindicato Nacional dos Docentes das Instituições de Ensino Superior (ANDES-SN). Esclarecemos ainda que a disposição em publicar o texto na Revista Brasileira de Educação se deve a dois motivos: em primeiro lugar, responder aos membros do GTTE que nos indicaram para realizar o trabalho encomendado e, em segundo lugar, porque acreditamos que as revistas se destinam a públicos, em parte, distintos. Além disso, entendemos que este trabalho se presta a uma elaboração coletiva - seja no âmbito estritamente acadêmico, seja no movimento sindical - que contribua para o combate ao produtivismo, cada vez mais apartado das necessidades da sociedade brasileira. 
Em O mal-estar na civilização, Freud discute a busca da felicidade e do prazer, perante os paradoxos da satisfação, no contexto da civilização, no século XX. A contribuição específica de Freud à política pode ser sintetizada, de forma esquemática, na ideia de que as paixões são reprimidas pela cultura. Nesse sentido, todos somos tomados por um mal-estar e, em alguma medida, somos "inimigos da civilização" (Gay, 1989, p. 493-494). Por tudo isso, a obra O mal-estar na civilização deve ser lida como uma profunda reflexão ética, sobre os paradoxos da busca da felicidade e os limites da civilização (Falbo, 2005, p. 147).

Examinemos melhor sua tese psicanalítica da política.

Para Freud, exceto no campo do pensamento religioso, isto é, metafísico, não é possível resolver a questão do propósito da vida. Contudo, de forma menos ambiciosa, podemos observar as condutas humanas e chegar à conclusão de que os homens querem ser felizes e assim permanecer. Essa procura apresenta dois aspectos: uma meta positiva - alcançar sentimentos de prazer; e uma meta negativa - evitar o sofrimento e o desprazer. A rigor, para Freud, apenas a consecução da meta positiva - o prazer - pode ser considerada efetivamente "felicidade".

Nesse sentido, o que geralmente se entende por "felicidade" provém da satisfação, de preferência repentina, de necessidades (instintos ou pulsões ${ }^{4}$ ) represadas. Por consequência, tal satisfação só é possível de se manifestar de forma episódica. Contudo, se a situação almejada pelo princípio do prazer se prolongar, ela produz tão somente um sentimento de contentamento muito, muito tênue, quiçá de indiferença.

Assim, se concordarmos com Freud, o "propósito da vida é simplesmente" o que ele denominou "o programa do princípio do prazer"s; embora bastante eficaz, o princípio do prazer está em desacordo com toda a realidade.

De fato, todo o universo parece conspirar contra a consecução desse princípio. Ou seja, a infelicidade é muito menos difícil de experimentar. O sofrimento ameaça-nos por três vias: o corpo - condenado à decadência e à dissolução; a natureza - que pode nos destruir sem aviso; e, finalmente, nossas relações com os outros.

No que tange às duas primeiras fontes de nosso sofrimento - o poder superior da natureza e a fragilidade de nossos corpos -, parece que, com relativa facilidade, nos submetemos ao inevitável, pois parecemos entender que "Nunca dominaremos completamente a natureza, e o nosso organismo corporal, ele

4 Neste artigo, não cabe a discussão sobre as opções dos tradutores (de língua inglesa e de língua portuguesa) acerca dos diversos conceitos freudianos. Contudo, é preciso alertar que, neste texto, com exceção das citações literais ao texto freudiano, seguimos as seguintes escolhas: em vez de instinto, ansiedade e repressão, optamos por utilizar pulsão, angústia e recalque.

5 Para Freud, "o princípio do prazer domina o funcionamento do aparelho psíquico desde o início” (Cf. Freud [1929/1930] 2006, p. 84). 
mesmo parte dessa natureza, permanecerá sempre como uma estrutura passageira, com limitada capacidade de adaptação e realização" (Freud, [1929/1930] 2006, p. 93).

$\mathrm{Na}$ verdade, o reconhecimento dessas limitações não nos paralisa. Ao contrário, através do reconhecimento do mundo da necessidade natural expandimos o mundo da liberdade humana por meio do trabalho coletivo. Laboramos para compreender e dominar a natureza, elaboramos poderosas próteses para expandir nossa capacidade corporal e mesmo intelectual. A ciência e a tecnologia são processo e produto desse trabalho coletivo. Pela mediação do trabalho, modificamos o mundo e a nós mesmos.

Contudo, diante de tantas e insuperáveis dificuldades, acabamos por moderar muito nossas reivindicações de felicidade e, mesmo, o princípio do prazer acaba por transformar-se naquilo que Freud chamou de "princípio de realidade".

Para Freud, o princípio de realidade entra em ação mitigando a busca imediata da obtenção de prazer. Em poucas palavras, não abrimos mão do prazer, mas o adiamos e o refreamos, o transformamos, posto que seria por demais penoso conseguir toda a cota de prazer que gostaríamos de obter aqui e agora. Ou seja, na maior parte do tempo, preocupamo-nos mais em evitar o sofrimento do que propriamente obter o prazer $^{6}$.

$\mathrm{Na}$ verdade, para Freud, a cultura, a civilização é o resultado do trabalho coletivo de sublimação das pulsões, isto é, uma forma "civilizada" de dar uma consequência à eterna necessidade da busca da satisfação a essas pulsões. Diz Freud:

a palavra "civilização" [Kultur] descreve a soma integral das realizações e regulamentos que distinguem nossas vidas das de nossos antepassados animais, e que servem a dois intuitos, a saber: o de proteger os homens contra a natureza e o de ajustar os seus relacionamentos mútuos. (idem, ibidem)

Contudo, a vida em sociedade é encarada, simultaneamente, como a terceira e mais poderosa fonte de nossos sofrimentos.

Se, com relação às outras duas fontes de sofrimento (a natureza e o corpo), as encaramos como necessárias e lutamos para contorná-las pelo trabalho, quanto à terceira fonte de nossos sofrimentos - a sociedade -, contudo, nossa atitude, de um modo geral, é diferente. O sofrimento advindo da vida em sociedade parece-nos mais penoso do que os oriundos de outras fontes: "Tendemos a encará-lo como uma espécie de acréscimo gratuito, embora ele não possa ser menos fatidicamente inevitável do que o sofrimento oriundo de outra fonte" (idem, p. 85).

6 Prazer ou felicidade são definidos como a satisfação de uma "pulsão" (ou instinto). 
Na época de Freud, muitos acreditavam que a sociedade seria a fonte de todas as nossas desgraças. Profetas nostálgicos anunciavam que seríamos mais felizes se retornássemos ao estado de natureza, que deixássemos livres, para obtenção de satisfação, todas as nossas pulsões. Em outras palavras, tais profetas afirmam que se deixássemos de ser humanos, se fôssemos capazes de abrir mão da civilização, enfim, seríamos felizes. Um paradoxo se estabelece: de um lado, construímos a civilização para proteger-nos da natureza e compensar nossas limitações físicas individuais; de outro lado, reconhecemos nessa construção humana a responsável pelos nossos maiores sofrimentos.

Assim como na época de Freud, neste início do século XXI, que é o nosso tempo, sua análise ganha ainda maior relevo, notadamente no que tange ao desenvolvimento tecnológico. Nas palavras de Freud:

Existe ainda um fator adicional de desapontamento. Durante as últimas gerações, a humanidade efetuou um progresso extraordinário nas ciências naturais e em sua aplicação técnica, estabelecendo seu controle sobre a natureza de uma maneira jamais imaginada. [...] Os homens se orgulham de suas realizações e têm todo direito de se orgulharem. Contudo, parecem ter observado que o poder recentemente adquirido sobre o espaço e o tempo, a subjugação das forças da natureza, consecução de um anseio que remonta a milhares de anos, não aumentou a quantidade de satisfação prazerosa que poderiam esperar da vida e não os tornou mais felizes. (idem, p. 94-95)

E Freud conclui: "Reconhecendo esse fato, devemos contentar-nos em concluir que o poder sobre a natureza não constitui a única precondição da felicidade humana, assim como não é o único objetivo do esforço cultural" (idem, ibidem).

Enfim, um mal-estar toma conta da civilização.

Um contentamento descontente parece estar presente em todos nós. Refreamos, sublimamos nossos impulsos em direção à cultura, construímos a civilização. A civilização volta-se contra a satisfação desses mesmos impulsos, pois a sociedade pressupõe a renúncia às pulsões.

Esta é a essência do mal-estar na civilização, segundo Freud: uma "“frustração cultural' domina o grande campo dos relacionamentos sociais entre os seres humanos" (idem, p. 104). Duas forças estão em luta permanentemente. De um lado, precisamos da civilização, da comunidade humana, da sublimação de nossos impulsos. De outro lado, precisamos satisfazer esses mesmos impulsos, reprimidos e sublimados - apenas parcialmente - pela sociedade. Um resto sobra. De um lado, caminhamos seguindo um impulso à repetição, agregar, repetir, mais do mesmo, cada vez em maiores agregados. Esse impulso, Freud designou de Eros, ou "pulsão de vida". A civilização é o resultado do trabalho de Eros. De outro lado, procuramos retornar ao status quo ante, voltar às origens, desagregar e começar de novo. Esse impulso, Freud denominou "pulsão de morte" (idem, p. 122). 
Aqui, contudo, é preciso precaver-nos contra uma interpretação simplista e maniqueísta dessas duas forças em eterna disputa:

O que chamamos habitualmente de vida é a articulação entre as duas dimensões. É preciso afastar todos os preconceitos: pulsão de vida na teoria freudiana nada tem a ver com o lado iluminado, do bem etc. Ela é morte se sozinha, pura instituição desabitada, sala vazia. Já a pulsão de morte é vontade de tudo de novo, de eterno recomeço que é pura destruição se não ganhar os contornos que the oferece a cultura com seus objetos e limites simbólicos. Assim, se dissociadas, as duas são morte. A vida que levamos só é vida porque feita da mistura delas. (Vieira, 2010, s/p.)

Nesse sentido, Freud ensina-nos que nunca houve um Paraíso; não há um Paraíso Perdido a ser encontrado. Também não é possível construir uma Nova Icária, na qual todo o mal-estar seria definitivamente banido. Sem dúvida, Freud não era um utopista ou um adepto da revolução socialista. Mas, mesmo assim, Freud admite que "uma mudança real nas relações dos seres humanos com a propriedade seria de muito mais ajuda do que quaisquer ordens éticas", postulações morais ou religiosas até então preconizadas por muitos reformadores sociais liberais (Freud, [1929/1930] 2006, p.146).

Freud encerra seu longo ensaio com um presságio:

Os homens adquiriram sobre as forças da natureza tal controle, que, com sua ajuda, não teriam dificuldades em se exterminarem uns aos outros, até o último homem. Sabem disso, e é daí que provém grande parte de sua atual inquietação, de sua infelicidade e de sua angústia. (idem, p. 147)

Enfim, para Freud, pulsão de vida e pulsão de morte entrelaçam-se necessariamente. $\mathrm{O}$ mal-estar na civilização é o resultado de formas antagônicas em confronto, é um sinal, um sintoma que uma luta está em processo.

\section{O FETICHISMO DO CONHECIMENTO-MERCADORIA: VALOR DE TROCA E VALOR DE USO NA ACADEMIA}

Se na seção anterior deste ensaio pretendemos trabalhar um pouco a noção de mal-estar em Freud, nesta segunda seção procuramos trabalhar a noção de conhecimento-mercadoria e as suas consequências práticas.

Marx abre assim sua obra magna O Capital:

A riqueza das sociedades onde rege a produção capitalista configura-se em "imensa acumulação de mercadorias", e a mercadoria, isoladamente considerada, 
é a forma elementar dessa riqueza. Por isso, nossa investigação começa com a análise da mercadoria. (Marx, [1890] 1994, p. 41)

E, em seguida, diz-nos:

A mercadoria é, antes de mais nada, um objeto externo, uma coisa que, por suas propriedades, satisfaz necessidades humanas, seja qual for a natureza, a origem delas, provenham do estômago ou da fantasia. Não importa a maneira como a coisa satisfaz a necessidade humana, se diretamente, como meio de subsistência, objeto de consumo, ou indiretamente, como meio de produção. (idem, p. 41-42)

Ou seja, Marx assinala, em primeiro lugar, que a mercadoria possui necessariamente valor de uso, ou seja, é capaz de satisfazer necessidades humanas, sejam elas provenientes do estômago ou da fantasia, enfim, a mercadoria precisa ter uma utilidade.

Contudo, se toda mercadoria tem uma utilidade (isto é, valor de uso), cada mercadoria é veículo material de um valor de troca. Diz Marx:

O valor de troca revela se, de início, na relação quantitativa entre valores de uso de espécies diferentes, na proporção em que se trocam, relação que muda constantemente no tempo e no espaço. Por isso, o valor de troca parece algo casual e puramente relativo, e, portanto, uma contradição em termos, um valor de troca inerente, imanente à mercadoria. (idem, p. 43).

Ora, nesse sentido, se tomadas como valores de uso, duas mercadorias (distintas) sempre serão incomensuráveis, consideradas como valores de troca, sempre será possível estabelecer uma relação quantitativa entre elas. Sendo assim, sempre poderão ser efetivamente trocadas, mediante alguma equivalência.

Ora, a sociedade capitalista, a sociedade das mercadorias, caracteriza-se precisamente pela subsunção do valor de uso ao valor de troca. E, nesse processo, o próprio trabalho humano transforma-se:

Se prescindirmos do valor de uso da mercadoria, só lhe resta ainda uma propriedade, a de ser produto do trabalho. Mas, então, o produto do trabalho já terá passado por uma transmutação. Pondo de lado seu valor de uso, abstraímos, também, das formas e elementos materiais que fazem dele um valor de uso. Ele não é mais mesa, casa, fio ou qualquer outra coisa útil. Sumiram todas as suas qualidades materiais. Também não é mais o produto do trabalho do marceneiro, do pedreiro, do fiandeiro ou de qualquer outra forma de trabalho produtivo. Ao desaparecer o caráter útil dos trabalhos neles corporificados, desvanecendo-se, portanto, as diferentes formas de trabalho concreto, elas não mais se distinguem umas 
das outras, mas reduzem-se, todas, a uma única espécie de trabalho, o trabalho humano abstrato. (idem, p. 44-45, grifos nossos)

Em síntese, aponta-nos Marx:

Esses produtos passam a representar apenas a força de trabalho humana, gasta em sua produção, o trabalho humano que neles se armazenou. Como configuração dessa substância social que lhes é comum, são valores, valores-mercadorias. (idem, p. 45, grifos nossos)

Em poucas palavras, Marx mostra-nos que o trabalho humano abstrato, ou seja, o dispêndio de trabalho humano em geral é a fonte criadora do valor.

O que determina a grandeza do valor, portanto, é a quantidade de trabalho socialmente necessário ou o tempo de trabalho socialmente necessário para a produção de um valor de uso. [...] "Como valores, as mercadorias são apenas dimensões definidas do tempo de trabalho que nelas se cristaliza”. (idem, p. 46, aspas no original)

No modo de produção capitalista, há um empuxo irresistível na conversão de todos os objetos e atividades úteis ao homem (sejam úteis ao estômago ou a fantasia, repetimos) em mercadoria. O que, na prática, significa que todos os objetos (ou atividades) tenderão a ser produzidos (ou desempenhadas) para serem mercadejados. Sob o capitalismo, em última instância, o valor de uso de um objeto é precisamente o seu valor de troca. Em outras palavras, em nossa sociedade, as coisas, as pessoas, e o próprio conhecimento científico sofre um empuxo à mercantilização, ou seja, a subsunção de seu valor de uso ao valor de troca. O conhecimento científico, nessa perspectiva, só tem valor se tem valor de troca, se é conversível em outra mercadoria, se pode ser mercantilizado, enfim.

A versão talvez mais pronta e acabada desse processo de conversão do valor de uso do conhecimento científico em mercadoria, ou seja, em valor de troca, é a forma-patente. Ou seja, aquele título que assegura ao "autor" de uma invenção sua propriedade privada e, portanto, seu uso exclusivo e alienável mediante pagamento.

Não é, portanto, casual que órgãos internacionais como o Banco Mundial (BM) e a Organização das Nações Unidas para a Educação, a Ciência e a Cultura (UNESCO) recomendam às chamadas "economias emergentes" o financiamento governamental e empresarial às atividades de pesquisa acadêmica, desde que essas tenham como horizonte a sua conversão em patentes. ${ }^{7}$ Aliás, o número de patentes é utilizado como índice de hierarquização, de ranqueamento entre países e centros de pesquisa.

7 Sobre essas proposições, ver BM (2000) e UNESCO (2006); cf. Neves e Pronko (2008). 
Ora, considerado esse empuxo irrefreável à produção de mercadorias, faz-se necessária a homogeneização tanto do produto final quanto do processo mesmo de criação do valor de uso. A rigor, só se pode falar em mercadorias se os bens úteis, os valores de uso, puderem ser reproduzidos, ou seja, produzidos repetidamente e, portanto, ter sua produção controlada externamente.

Embora o conhecimento científico não seja em nada similar a uma mesa ou uma cadeira, para que o conhecimento seja efetivamente convertido em mercadoria é necessário que a sua produção emule a produção de outras mercadorias. Em outras palavras, a produção do conhecimento precisa ser submetida a métodos, processos e finalidades o mais próximo possível à produção mercantil de outras mercadorias.

Se isso for verdade, as repercussões na Academia não poderiam deixar de ser sentidas. Com efeito,

[...] o governo Fernando Henrique Cardoso criou, em 1998, os mestrados e doutorados profissionais. Com tal medida, efetivamente, esse governo iniciou o processo de desmonte do modelo "rígido" da pós-graduação preexistente, destinado prioritariamente a desenvolver a ciência e a tecnologia e a formar novos cientistas, fincando as bases para a introdução do novo modelo educacional flexível proposto pelo BM-UNESCO. (Neves; Pronko, 2008, p. 136)

O Governo Lula da Silva (2003-2010), pelo menos nesse aspecto, deu prosseguimento às bases estabelecidas pelo governo anterior. Nesse sentido, destacam-se: o Plano Nacional de Pesquisa e Pós-Graduação (PNPG) 2005-2010 , e a portaria n. 07/2009 do MEC, que regulamenta o mestrado profissional. ${ }^{9}$

Sobre o PNPG, Lúcia Neves e Marcela Pronko (2008, p. 137) nos dizem:

Nessa perspectiva, a pós-graduação brasileira, que até os anos finais do século XX esteve voltada para a efetivação de atividades de pesquisa, passou a se constituir também, de forma significativa, em espaço de formação de "capital humano" especializado para todos os segmentos do mercado de trabalho e de convivência social.

Em síntese, segundo as autoras (idem, p. 171),

A chegada do Partido dos Trabalhadores ao governo em 2003 não altera substantivamente nem a direção nem as formas institucionais para o desenvolvimento das políticas C\&T no país. Muito pelo contrário, o governo Lula da Silva reafirma a prioridade da inovação tecnológica como foco estratégico, que a consolida como uma proposta de C\&T na ótica do capital e aprofunda os mecanismos que

8 Sobre o tema, ver Neves e Pronko (2008).

9 Sobre o tema, ver Rodrigues (2010). 
subordinam essa política aos imperativos da produtividade e da competitividade empresariais. De fato, foi durante o primeiro mandato de Lula da Silva que obtiveram aprovação importantes instrumentos legais nessa direção, quais sejam, a Lei de Inovação ${ }^{10}$, a chamada "Lei do Bem" e as Parcerias Público-Privadas - PPPs.

$\mathrm{Na}$ verdade, tais medidas (tomadas aqui apenas a título de exemplo) dão apenas prosseguimento ao processo de subsunção do valor de uso social do conhecimento à forma-valor, ou seja, a conversão do conhecimento em conhecimento-mercadoria, ou seja, à dupla incorporação da ciência à produção capitalista.

Marx, no capítulo XIII d'O Capital - "A maquinaria e a indústria moderna”-, mostra-nos com toda a crua clareza o papel desempenhado pela ciência, pela técnica e pela tecnologia sob o uso capitalista: "Poder-se-ia escrever toda uma história das invenções, feitas a partir de 1830, com o único propósito de suprir o capital com armas contra as revoltas dos trabalhadores" (Marx, [1890] 1994, p. 499).

Em poucas palavras, Marx mostra-nos como a ciência e a tecnologia são utilizadas pelo capital como meio de ampliar a exploração da classe trabalhadora, aumentando-lhe a produtividade.

Portanto, se já nos séculos XVIII e XIX estava claro, para o capital, o poder material da ciência, hoje se trata de estabelecer mecanismos objetivos de conversão da potência espiritual do conhecimento em ato material. Para tal, vislumbramos pelo menos dois processos articulados.

De um lado, o atual Sistema de Ciência, Tecnologia e Inovação estabelece regras mercantis para a própria produção do conhecimento: a regra atual de concessão de financiamentos é a mesma utilizada para a concorrência pública da construção de estradas - o edital. Com efeito, para vencer a "concorrência", os pesquisadores consorciados deverão demonstrar sua "capacidade técnica" de produção, por meio de indicadores claros e precisos, tais como o volume de sua produção anterior e a previsão dos produtos resultantes da investigação [sic]. Para garantir a continuidade da produção científica, os consórcios de pesquisa estabelecerão uma disciplina interna rígida, de cumprimento de tempos e movimentos, segundo o cronograma preestabelecido e ratificado pela agência de fomento. Obviamente, caberá a cada equipe de pesquisa o desenvolvimento de parcela preestabelecida do trabalho científico: do pesquisador sênior ao bolsista de iniciação científica, passando pelos mestrandos e doutorandos, cada qual com sua tarefa, todos em ordem unida sob a supervisão do pesquisador-líder e todos vigiados pelos prazos das agências de fomento.

Assim, cada vez mais, a produção do conhecimento assume a forma do trabalho fabril, como descreveu Marx:

10 Lei n. 10.973, de 2 de dezembro de 2004. Disponível em: <http://www.planalto.gov.br/ ccivil_03/_Ato2004-2006/2004/Lei/L10.973.htm>. 
Na manufatura e no artesanato, o trabalhador se serve da ferramenta; na fábrica, serve à máquina. Naqueles, procede dele o movimento do instrumental de trabalho; nesta, tem de acompanhar o movimento do instrumental. $\mathrm{Na}$ manufatura, os trabalhadores são membros de um mecanismo vivo. $\mathrm{Na}$ fábrica, eles se tornam complementos vivos de um mecanismo morto que existe independente deles. (idem, p. 483)

Embora saibamos que o atual estágio de subordinação da produção científica ainda é análogo à subsunção formal do trabalho ao capital, ${ }^{11}$ qualquer semelhança com a imagem gerada pela citação anterior não é mera coincidência. Enfim, os métodos de organização do trabalho científico ultrapassaram a forma artesanal, atingiram uma forma manufatureira e caminham para uma forma quasi-industrial.

Nesse sentido, os consórcios de pesquisa deverão prever os “produtos” que precisarão emergir de seu trabalho coletivo, de preferência, produtos com repercussões práticas, isto é, "inovações”.

O chamado Livro Verde, do Ministério de Ciência e Tecnologia (MCT), publicado em 2001, aponta com clareza meridiana a fusão dos dois aspectos finalidade e processo:

Em primeiro lugar, [as ciências humanas e sociais] deverão provar seu valor em meio a uma onda de demanda por eficiência, lucratividade e resultados, em que o avanço tecnológico é a chave para o aperfeiçoamento do mercado e a criação de emprego. Em segundo lugar, serão desafiadas a enfrentar questões novas e prementes que estão surgindo no contexto de grandes mudanças sociais e econômicas, crescente interdependência entre países e pressões cada vez maiores sobre os indivíduos e famílias. Finalmente, serão instigadas a utilizar integralmente as novas tecnologias, que vêm permitindo o desenvolvimento de novas ferramentas e infraestrutura de pesquisa. (Brasil. MCT, 2001, p. 28 apud Neves; Pronko, 2008, p. 177)

Ou seja, há um segundo aspecto, claramente articulado com o primeiro, a saber: o estabelecimento de uma lógica ou "ídeo-lógica" que estabelece a seguinte equação:

\section{$\mathrm{Cc} \rightarrow \mathrm{Tc} \rightarrow \mathrm{In} \rightarrow \mathrm{dE} \rightarrow \mathrm{dS}$}

11 Sobre as noções de subsunção formal e real do trabalho ao capital, ver Marx ([1890] 1994, vol. II), Marx (1975). 
Em palavras, diríamos simplesmente que "a Ciência $\left(C_{c}\right)$ deve se desdobrar em Tecnologia (Tc) que, por sua vez, deve produzir Inovaçôes (In), que, por sua vez, incrementam o desenvolvimento Econômico (dE), o qual inevitavelmente levará ao 'tão sonhado' desenvolvimento Social' (dS). ${ }^{12}$

Ora, se essa equação ideológica for tomada como verdadeira, então se deduz que a elevação da produtividade científica é uma necessidade para o Brasil mais rapidamente atingir o desenvolvimento Social. ${ }^{13}$

Portanto, o produtivismo é o resultado lógico-necessário da subsunção do valor de uso do conhecimento ao seu suposto valor de troca. Em outras palavras, a hegemonia da ideologia do produtivismo - com todas as suas consequências - é um meio pelo qual se procura simultaneamente acelerar, baratear e controlar a produção de conhecimento-mercadoria, seja na forma de artefatos tecnológicos, patentes de produtos ou processos, ou mesmo de mercadoria-educação, isto é, de força de trabalho qualificada, segundo as demandas do capital. O produtivismo é fantasma-fetiche que assombra/seduz, com promessas e ameaças, a Academia.

\section{MAPEANDO O MAL-ESTAR NA ACADEMIA}

Nesta seção, apresentaremos um breve e, ao mesmo tempo, variado levantamento disso que estamos denominando o mal-estar na Academia. Ao final da seção, procuraremos estabelecer as convergências, diferenças e contradições na crítica do produtivismo.

A universidade brasileira vem tematizando, de longa data, qual a sua finalidade social em meio ao conflito de interesses entre capital e trabalho. A subsunção do valor de uso social de sua produção científica, técnica e artística ao valor de troca mercantil expressa-se em uma crescente insatisfação por parte dos docentes pesquisadores. Ao lado de manifestações de resistência encontramos também a apatia ou a adesão ao processo em curso, sob argumentos que naturalizam as leis do mercado como o horizonte possível para a sociedade brasileira.

Em recente estudo, Mocelin (2009) analisa o desenvolvimento da ciência no Brasil e busca compreender como a comunidade científica lida com a acirrada competição entre os pesquisadores por mais acesso a recursos financeiros e prestígio social.

Ao analisar os dados disponíveis no CNPq sobre o aumento exponencial do número de pesquisadores e de grupos de pesquisa, bem como o incremento de produção de artigos e livros, e dos meios de divulgação da produção científica, o

12 Neves e Pronko (2008, p. 165) revelam esta "ídeo-lógica" presente no chamado Livro Verde da Ciência e da Tecnologia.

13 Poderíamos, talvez, dizer que se trata de uma extensão do aspecto "macro" da conhecida teoria do capital humano (Cf. Frigotto, 1989). 
autor constatou uma possível relação entre a concorrência entre os pesquisadores e a formação de grupos de pesquisa, como estratégia de sobrevivência.

Em suas conclusões, o autor, embora não defenda a ideia de que a concorrência, tal como se estabelece, seja adequada ao desenvolvimento científico, aponta a prática da organização em grupos como algo benéfico ao trabalho acadêmico e constata que novas gerações de pesquisadores já são formadas sob esse novo paradigma, vivenciando a concorrência como algo inerente ao fazer científico. $\mathrm{O}$ estudo reforça, em grande parte, os argumentos que desenvolvemos anteriormente, ou seja, sobre a contradição entre a coerção a que a comunidade científica se sente submetida, pelo ritmo acelerado das transformações dos processos de trabalho instaurados na Academia, e o desejo de contribuir para o sistema brasileiro de ciência e tecnologia, o que possibilita, também, obter o reconhecimento dos pares.

No âmbito desse conflito, sinalizamos para alguns desafios a enfrentar como, por exemplo, a que patamares de más práticas acadêmicas nos acostumaremos e como lidaremos com as consequências se quisermos preservar o valor de uso social de nossa produção e não apenas seu valor de troca mercantil.

Se esse quadro se configura para a universidade em sua totalidade, os dados coletados por Mocelin (2009) mostram que as maiores taxas de expansão da comunidade científica, no período considerado (1993-2006), ocorrem principalmente no âmbito das ciências humanas e das ciências sociais aplicadas, em particular. Assim, essa questão diz respeito diretamente àquilo que temos observado no campo da pesquisa educacional.

Recorremos a Gatti (2007) para recuperar historicamente o percurso da área da educação como um dos campos do conhecimento que vivencia grande expansão e ao mesmo tempo enfrenta pressões diferenciadas perante outras áreas mais consolidadas e reconhecidas pela comunidade científica brasileira. Os diferentes períodos pelos quais passou o campo ilustram a fragilidade da área se considerarmos o tempo de maturação necessário para o adensamento de qualquer conhecimento científico.

Segundo a autora, podemos localizar na década de 1960, com a criação e implementação dos programas de pós-graduação em educação, o incremento da pesquisa educacional no universo das instituições de ensino superior no Brasil. Segundo a autora, uma certa convergência tanto do ponto de vista das temáticas quanto das referências teórico-metodológicas caracterizaram a produção da área. Sucessivamente passamos dos estudos com um enfoque psicopedagógico centrado no aluno e nas teorias da aprendizagem - o período escolanovista - para um segundo momento marcado pelo nacional desenvolvimentismo, em que as ciências sociais instrumentalizavam a articulação entre sociedade e educação, num viés predominantemente funcionalista. 
No período militar dos anos 1960 e 1970, com a criação da pós-graduação, intensificou-se a pesquisa e a formação de quadros para o nível superior, em que o tecnicismo e a teoria do capital humano se coadunavam com o novo projeto desenvolvimentista que buscava ampliar o sistema de ciência e tecnologia, de forma que alavancasse o país para uma maior integração ao capitalismo mundial, adequadamente mais competitiva.

Nos anos de 1980, prevaleceram os estudos educacionais mais críticos, movidos pelo processo de redemocratização da sociedade. Foi o momento em que as questões educacionais estiveram relacionadas às questões sociais com ênfase nos interesses de classe. A partir dos anos de 1990, as teorias pós-modernas passaram a disputar a hegemonia no campo educacional, embora as teorias críticas, embasadas no materialismo histórico, ainda estejam presentes.

Hoje, podemos constatar que a área realiza um grande esforço para obter o respeito e o reconhecimento como campo de conhecimento científico consolidado. Talvez por conta do afã por legitimar o campo educacional, aceitou-se o desafio produtivista instaurado pelo mercado do conhecimento, e hoje nos deparamos com as indesejáveis consequências desse processo.

Uma das questões que estão tornando-se evidentes é a da fraude acadêmica, como consequência, naturalizada como inevitável, diante da diferença entre o tempo necessário para a produção do conhecimento e a pressão para a apresentação de resultados.

A publicação tornou-se condição para a obtenção de financiamento à pesquisa, bolsa produtividade, melhores notas no ranqueamento da pós-graduação, prestígio junto aos pares, participação em eventos acadêmicos nacionais e internacionais etc.

No entanto, principalmente no âmbito das ciências humanas, a obtenção de resultados nem sempre pode ser prevista em prazos muito estreitos ou facilmente previsíveis, o que tem levado a comunidade a usar de diversos estratagemas que desagradam e degradam, como já dissemos, todos os envolvidos na produção mercantil do conhecimento.

Essa não é uma questão exatamente nova, mas houve uma agudização do problema a ponto de ter se convertido, ela mesma, em tema de pesquisa.

Já em 1992, em um encarte da revista Ciência Hoje, Assis (1992) elaborava uma reflexão intitulada "Conviver com a fraude", em que afirmava que, se a Ciência necessita de liberdade para se desenvolver, o uso que os indivíduos farão dela não deve inibir a publicação de trabalhos científicos "porque pode haver fraude". Para ele, os indivíduos inescrupulosos repartem-se por todas as atividades humanas. $\mathrm{O}$ fato, porém, de que a ciência tem tanto prestígio na sociedade impõe ao cientista a reflexão sobre a ética do exercício profissional.

Quase duas décadas se passaram, e hoje a comunidade científica se interroga sobre como resistir à fraude que decorre não da falta de caráter de alguns pesqui- 
sadores mas de um processo crescente de alienação em relação ao efetivo valor de uso social do trabalho produzido. As pressões por maior produtividade, a concorrência por mais verbas, a diminuição dos tempos para maturação de resultados deixam, de ser uma decisão que afeta cada indivíduo em particular, com liberdade de ação, para constituir-se em mecanismos de constrangimento coletivo por meio de instrumentos aparentemente objetivos e neutros, como são os instrumentos de avaliação e ranqueamento.

Em 2008, Sérgio Ferreira expressa outro tipo de preocupação ao analisar o aumento significativo dos trabalhos publicados por brasileiros em periódicos internacionais, e conclui que não é suficiente que comemoremos o crescimento quantitativo da produção no cenário internacional, mas que precisamos estar atentos à qualidade do que publicamos. Para o autor, os sistemas objetivos de avaliação são considerados confiáveis. Ele refere-se, em especial, à avaliação de impacto, ou seja, qual o número de vezes que um artigo é citado. Esse seria um critério "justo" para aferir o interesse que o artigo desperta na área e que representaria o reconhecimento da sua relevância. No artigo em questão, não há um questionamento sobre os rumos da pesquisa científica, sua motivação e ao que e a quem ela beneficia, o que nos faz supor que o autor parte da premissa de que o conhecimento científico é neutro e possui um valor universal, servindo indistintamente a todos os setores da sociedade. Para ele, maiores estímulos financeiros e maior rigor nos critérios de avaliação nos conduziriam a patamares mais elevados no ranking internacional.

Em outra direção, Castiel e Sanz-Valero (2007) questionam o fetichismo de que se reveste o artigo científico e advertem que se estima que metade dos trabalhos publicados na área das ciências sociais jamais será citada. Eles apontam que na área de saúde pública o aumento quantitativo de publicações não se refletiu em melhorias na saúde das populações. Para eles, faz-se urgente a retomada da discussão em torno das questões éticas que devem nortear o fazer acadêmico, pois hoje há uma espécie de naturalização de diversos procedimentos fraudulentos que são vistos como uma forma de gerenciamento do currículo. Eles citam, dentre outros, procedimentos como plágio, plágio de si mesmo, aumento de autores por artigo, troca de favores pela citação de colegas que retribuem com citações em seus textos, uso de referências sem consulta aos textos citados, fatiamento dos resultados de pesquisa de forma que rendam mais artigos e trabalhos apresentados em congressos. A lista de possibilidades de burlas (ou de gerenciamento de currículo) parece não ter fim.

Os autores destacam a dimensão mercantil que o conhecimento científico assume, tanto pelo capital simbólico que gera, ao ampliar prestígio e reconhecimento, quanto pela relação mercantil direta que pode assumir, por exemplo, ao restringir o acesso dos usuários dos resultados das pesquisas, impondo a cobrança de pagamento, o que caracteriza a produção científica como uma produção individual e apropriação como propriedade privada. As duas dimensões escamoteiam que, numa sociedade de classes, o trabalho coletivo necessário à produção do conhecimento é mascarado e o valor de uso social é subsumido ao valor de troca. Os autores 
concluem que, mais do que encontrar mecanismo de controle a esses tipos de práticas, que perderam o sentido ético do trabalho acadêmico, importa compreender os significados da produção do conhecimento em uma economia globalizada que mercantiliza todas as dimensões da vida. Só assim poderemos distinguir o valor de uso social da ciência, para a melhoria da vida dos seres humanos, da ciência que ao se desenvolver em si apenas, ainda que involuntariamente por parte de muitos pesquisadores, acaba contribuindo para a manutenção de um sistema baseado em grandes desigualdades sociais.

Por último, citamos artigo recente publicado na imprensa espanhola em que a autora (Mangas Martín, 2010) denuncia o desperdício de recursos públicos com publicações que não são frutos autênticos de pesquisa e com o financiamento de projetos de pesquisa que, na realidade, vão financiar viagens ao exterior para levantamento de dados, já disponíveis na internet ou mesmo nas bibliotecas locais. Geralmente são trabalhos cujo objeto de pesquisa é tão geral que tem pouca possibilidade de gerar algum conhecimento novo realmente relevante.

Araceli Mangas Martín chama a atenção também para os aspectos institucionais que vão sendo fraudados, uma vez que os professores são avaliados de acordo com os projetos aprovados, trabalhos publicados, teses orientadas, sem que haja uma real preocupação com a origem, o significado e a relevância do que é produzido.

Assim, com os breves exemplos citados, queremos caracterizar que, embora a comunidade científica nacional e internacional se curve aos ditames produtivistas, mesmo entre os que o fazem considerando que contribuem para o avanço da ciência, há uma grande preocupação com a qualidade do que é produzido. Diante dos dados do aumento das iniquidades sociais, somos assolados pelo mal-estar da civilização que nos trouxe ao século XXI com tantas angústias como as enumeradas por Freud e ainda caudatárias das raízes desvendadas por Marx. O produtivismo, como expressão do fetichismo do conhecimento-mercadoria, precisa ser enfrentado.

No campo educacional, essa tarefa parece ser ainda mais árdua. A história da pesquisa em educação é recente e ainda busca consolidar sua pauta temática e seus referenciais teóricos e metodológicos. Grande tem sido o esforço para enquadrar-se nos parâmetros avaliativos que emanam de outras áreas já consolidadas e reconhecidas. Nunca o discurso hegemônico atribuiu à educação um papel tão relevante quanto agora. No entanto, quando os esforços dos pesquisadores se fazem na direção de radicalizar esse discurso, na direção dos interesses legítimos da maioria da sociedade, muitos são os empecilhos. As exigências produtivas nos distraem, nos dividem, fragmentam nossos esforços, superficializam nossas produções, aligeiram nossa elaboração, nos confinam ao fazer em si nos apartando do para si, da reflexão sobre o valor de uso social para a classe trabalhadora dos resultados do que produzimos num cotidiano amesquinhado.

A grande contradição que enfrentamos para resistir, agora, ao produtivismo é que fomos perdendo as articulações com os setores da sociedade que 
poderiam significar uma alternativa para a nossa necessidade de sermos felizes naquilo que fazemos.

Assim, ficamos prisioneiros do sistema que criticamos, participamos da concorrência que condenamos, aprimoramos a avaliação que nos subjuga. Excedemo-nos nas horas de vida dedicada ao trabalho - vida morta. ${ }^{14}$

Moreira (2009), em recente artigo, utiliza-se do conceito de performatividade (concebido por Stephen Ball) para analisar os processos avaliativos que incidem sobre a pós-graduação em educação no Brasil. Seu texto é ilustrativo das consequências de tais processos, pois aponta para "as novas possibilidades de controle, mensuração e regulação no âmbito dos programas [de pós-graduação]” (Moreira, 2009, p. 25).

Segundo o autor, instaurou-se, a partir desse clima gerado pelos processos avaliativos, uma profunda insatisfação por parte dos docentes e que contamina todo o ambiente institucional. Focalizando a avaliação - a partir da bibliografia produzida na área, sobre os docentes pelo incremento da produção e divulgação dos resultados de pesquisas por meio de publicações, participações em congressos etc.--, o autor enfatiza que a avaliação quantitativa vem induzindo o que ele chamou de "indústria da produção". Assim, Moreira (2009) encontrou no conceito de performatividade uma expressão adequada para expor o que se verifica hoje no âmbito da pós-graduação brasileira. Ou seja, a exigência de desempenho acompanha a trajetória dos docentes e das instituições de forma constante em que, segundo Moreira (2009), citando Ball (2004), "ao Estado regulador associa-se o Estado auditor, sempre avaliando resultados" (Moreira, 2009, p. 33). O autor conclui dizendo que, no momento em que as pressões impostas pelos sistemas avaliativos quantitativos vêm gerando a insatisfação, desesperança e adoecimento dos docentes é a hora de construir uma cultura contra-hegemônica recuperando os verdadeiros valores de uso sociais de que se deve revestir a ciência produzida na pós-graduação.

Aos poucos estudos referidos aqui, em meio a uma vasta produção existente na área, destacaríamos ainda a análise efetuada pelas coordenadoras da área de educação junto à CAPES, num esforço de síntese para dar a conhecer aos pesquisadores e aos programas a forma como a avaliação vem sendo implementada. Elizabeth Macedo e Clarilza Prado de Souza explicitam a intenção de desconstruir o que consideram uma certa postura nostálgica que detectam na área e à qual elas se contrapõem com argumentos que optamos por reproduzir de forma mais extensa.

Preocupa-nos a nostalgia (restaurativa) de um tempo outro que subjaz ao discurso crítico do produtivismo. Para apoiar essa nostalgia, postula-se uma relação não sustentada entre quantidade e qualidade da produção: num tempo em que a produção era menor, era certamente, e por isso, melhor. Uma avaliação

14 Sobre o tema, ver Sguissardi e Silva Jr. (2009), além de dossiê sobre trabalho docente na revista Universidade e Sociedade, n. 45, jan. 2010. 
pouco sistemática da produção em educação hoje não parece deixar dúvidas de que ela é mais consistente do que o que se produzia nos anos de 1970 e 1980. As teses e dissertações recentes têm mais profundidade teórica, se comparadas com a média dos trabalhos defendidos nos anos de 1970 e 1980. Nossos periódicos, além de mais numerosos, têm mais qualidade. A plêiade de livros que vemos hoje em eventos não é apenas quantitativamente maior, mas espelha uma produção própria dos pesquisadores da educação no Brasil em contraposição a uma ampla maioria de manuais e adaptações de literatura estrangeira que predominava nos anos de 1970. (Macedo; Souza, 2010, p. 175)

As autoras concluem que, embora reconheçam justa a demanda da área para que, no processo avaliativo, o quesito da inserção social seja considerado relevante, no entanto é a trajetória consistente de incremento da produção científica que tem nos dado o respeito dos pares e da comunidade científica em geral.

Entendemos que, mais uma vez, a avaliação está sendo vista pela área a partir dela mesma, ainda reforçando uma consciência em si. O movimento da consciência em direção ao outro (à sociedade), que nos permitiria a construção da consciência para si, ainda é tênue, tanto nas manifestações favoráveis à forma como vem se dando a avaliação - indutora das práticas acadêmicas - quanto daquelas que são críticas, mas apenas revelam as consequências da avaliação na vida dos docentes e das instituições.

Acreditamos que o desafio, hoje, seja o de transitarmos em direção ao outro, ou seja, à sociedade em sua totalidade e à classe trabalhadora, em especial. Sem essa conexão dificilmente poderemos retornar a nós mesmos, plenos do sentido qualitativo do nosso fazer que não se constrói a partir de nós exclusivamente, mas que necessita da mediação da interlocução com as necessidades do outro, sem a qual todo o nosso esforço ficará apartado dos resultados concretos que desejamos ver refletidos numa sociedade emancipada.

Mais do que discutir o produtivismo, precisamos resgatar o valor de uso social de nosso trabalho, superando o valor de troca material e simbólico que caracteriza o trabalho intelectual produzido no meio acadêmico.

\section{À GUISA DE CONCLUSÃO}

Tudo o que era sólido e estável se desmancha no ar, tudo o que era sagrado é profanado e os homens são obrigados finalmente a encarar sem ilusões a sua posição social e as suas relaçôes com os outros homens. Marx; Engels, [1848] 2002, p. 43

Um mal-estar assombra a Academia: o mal-estar provocado pelo fetiche do conhecimento-mercadoria e o seu canto de sereia - o produtivismo. Assim abrimos 
o nosso ensaio em uma óbvia alusão à frase inicial do Manifesto Comunista, de Marx e Engels.

O que trabalhamos para explicitar é que o mal-estar que permeia a Academia brasileira (e quiçá a mundial) é resultado de dois movimentos opostos e, nesse sentido, inconciliáveis.

De um lado, o desejo de produzir um conhecimento vivo, consistente e transformador da realidade, um conhecimento que necessariamente seria desvelador das relações estabelecidas e, portanto, transformador e até mesmo subversivo.

De outro lado, a busca pelo reconhecimento da sociedade (burguesa), da comunidade científica, inclusive das entidades estatais de fomento à pesquisa, nos conduz a práticas cada vez mais condizentes, conformados às formas, aos objetivos e às finalidades postos pela força social hegemônica.

Em outras palavras, o pesquisador que aspira e procura criar o novo, produzir contra o estabelecido - de forma contraditória -, procura, cada vez mais, estabelecer-se dentro do sistema de C\&T, precisa, para tal, recalcar a emergência do novo.

A Academia debate-se, então, entre duas perspectivas, na produção do conhecimento: de um lado, o valor socialmente útil e transformador; de outro lado, o valor de troca mercantil e, portanto, conformado à lógica dominante. É essa tentativa infrutífera de conciliação que produz a sensação de mal-estar que assola a Academia.

Neste texto, pretendeu-se refletir sobre esse mal-estar, primeiramente, recuperando a noção freudiana de mal-estar. Em seguida, trabalhou-se a ideia de que o conhecimento está sendo convertido em mercadoria, ou seja, que o capital está empreendendo, de maneira bastante eficiente e eficaz, ao processo de subsunção do valor de uso social do conhecimento à forma-valor, ou seja, a subordinação reificada da ciência à produção capitalista. Finalmente, na terceira parte desta apresentação, se resenharam e se confrontaram algumas das inúmeras contribuições críticas já publicadas sobre as transformações pelas quais a Academia vem passando a partir da busca da elevação da produtividade científica, ou seja, da elevação do produtivismo à condição de fetiche.

Para fazer ciência, acabamos enredados e paralisados no chamado sistema nacional de ciência e tecnologia - que nos serve de prisão. Prisão que construímos com grande dedicação.

Lembremos que, em 1998, Frigotto, referindo-se à necessidade da publicação do livro Educaşão e crise do trabalho: perspectivas de final de século, afirmava:

A coletânea se origina do desconforto que o GT Trabalho-Educação da ANPEd vinha percebendo na produção acadêmica dos seus componentes ou mais amplamente na área e áreas afins ao longo particularmente da última década, sobre as relações entre o mundo do trabalho, da educação escolar, da formação humana ampla e da qualificação técnico-profissional. (Frigotto, 1998, p. 15-16) 
Daquela coletânea resgatamos os questionamentos formulados por Kuenzer e Arroyo e que nos parecem conter elementos ainda fecundos para nossa reflexão e ação. Questionamentos que apontam para a necessidade de transitarmos do em si da academia em direção ao outro, à sociedade, para então, talvez, podermos retornar a um para si denso de sentido social.

Questionava Kuenzer (1998, p. 74):

Até que ponto a produção do GT [Trabalho-Educação] tem, de fato, contribuído para o enfrentamento das questões concretas relativas à educação dos trabalhadores, ultrapassando o discurso generalizante, que termina por constituir-se contemplativo?

Em tempos de globalização da economia e reestruturação produtiva, marcados pela crescente exclusão, quem é o objeto de estudo e o compromisso político do GT?

E perguntava Arroyo (1998, p. 139-140):

O conhecimento acumulado tem sido incorporado na teoria da educação básica, na educação de jovens e adultos, na formação profissional, na formação de professores, nas reformas curriculares, ou tem alimentado apenas nosso diálogo interno no GT [Trabalho-Educação]? Quem lê nossos textos? Que práticas educativas motivam? Que aspectos da teoria pedagógica e curricular eles alimentam? O que trazemos para o diálogo com a teoria pedagógica?

Caberia, por fim, perguntarmo-nos por que persistimos em construir nossa própria prisão.

Marx encerra o primeiro capítulo d'O Capital com a célebre seção "O fetichismo da mercadoria: seu segredo".

A mercadoria é misteriosa simplesmente por encobrir as características sociais do próprio trabalho dos homens, apresentando-as como características materiais e propriedades sociais inerentes aos produtos do trabalho; por ocultar, portanto, a relação social entre os trabalhos individuais dos produtores e o trabalho total, ao refleti-la como relação social existente, à margem deles, entre os produtos do seu próprio trabalho. [...] Uma relação social definida, estabelecida entre os homens, assume a forma fantasmagórica de uma relação entre coisas. Para encontrar um símile, temos de recorrer à região nebulosa da crença. Aí, os produtos do cérebro humano parecem dotados de vida própria, figuras autônomas que mantêm relações entre si e com os seres humanos. É o que ocorre com os produtos da mão humana, no mundo das mercadorias. Chamo a isto de fetichismo, que está sempre grudado aos produtos do trabalho, quando são gerados como mercadorias. É inseparável da produção de mercadorias. (Marx [1890] 1994, p. 81) 
Analogamente, podemos afirmar que o conhecimento-mercadoria e o sistema de ciência e tecnologia nos parecem figuras autônomas que nos governam, nos impelem a trabalharmos numa direção em que não acreditamos.

Os sujeitos concretos que se entendem membros da Academia precisam incluir aqueles que, efetivamente, podem dar algum sentido ao nosso trabalho - o qual julgamos muito importante - para com eles produzir o novo.

Talvez para nós, orgulhosos membros da Academia, ainda faça algum sentido a noção de classe trabalhadora e a exploração capitalista.

\section{PS: MAIS UM ESTRANHO ENTRE NÓS}

Para nossa imensa satisfação, a apresentação da versão original do texto, no GT Trabalho-Educação, propiciou um inestimável debate acerca das questões levantadas. Não foi possível, naquele momento, e tampouco o é, agora, discutir (e muito menos responder) a tantas e tão complexas questões. Contudo, entendemos que devemos acrescentar, a título de postscriptum, a reflexão que se segue, esboçada, na ocasião, em resposta a um tipo de questionamento que emergiu no debate: Como medir, de maneira mais adequada e menos perversa, a produtividade do pesquisador e a qualidade da pesquisa cientifica?

Eis a nossa resposta, provisória e incompleta:

Desde muito antes de nascer, a criança é falada. E as tecnologias médicas, tais como a contemporânea ultrassonografia colorida $3 \mathrm{D}$, contribuem muito para isso. Mas, finalmente, quando a criança pequena ingressa no mundo da linguagem (por meio da chamada língua materna), logo percebe que - embora potente e fascinante - a linguagem não é capaz de esgotar todas as possibilidades do mundo, todas as dimensões do próprio sujeito falante. Em uma frase, o sujeito não se resume ao que dele falam ou ao que ele próprio consegue falar. Há sempre um desvão. Percebido, então, o desvão, o sujeito persegue aquele significante que falta(ria), que supostamente preencheria esse desvão. Procura e não acha. Então, a assunção dessa falta (ou falha) acaba por gerar profunda angústia. O mundo do falante ameaça desabar se não houver a palavra que recobriria a falha, que responderia à pergunta do sujeito ao mundo (da própria linguagem).

Pois bem, a pergunta Como medir, de maneira mais adequada e menos perversa a produtividade do pesquisador e a qualidade da pesquisa cientifica?, na verdade, funciona como um biombo à pergunta recalcada Por que medir? Se à primeira é impossível responder, à segunda pode-se ensaiar uma resposta, aliás, resposta conhecida pelos colegas da Academia:

Ora, medimos para esconder o fato de que, na sociedade capitalista, não há lugar, poder, dinheiro, enfim, mercadorias para todos. Sabemos disso. Posto que não há mercadoria para todos, é preciso criar (manter e refazer) mecanismos 
supostamente objetivos e impessoais que terão a finalidade de aliviar a angústia provocada pela resposta. Em outras palavras, mede-se para simultaneamente justificar e manter alguns poucos gozando a mercadoria (e, em particular, o conhecimento-mercadoria).

\section{REFERÊNCIAS}

Arroyo, Miguel. Trabalho-educação e teoria pedagógica. In: FrigotTo, G. (Org.). Educação e crise do trabalho: perspectivas de final de século. Petrópolis: Vozes, 1998. Assis, Jesus de Paula. Conviver com a fraude. Ciência Hoje - Encarte. Rio de Janeiro, v. 15, n. 85, p. 1-4, out. 1992.

BALL, Stephen J. Performatividade, privatização e o pós-Estado do bem-estar. Educação Es Sociedade, v. 25, n.89, p.1105-1126, 2004.

$\mathrm{BM}$ - Banco Mundial. Educación superior en los países en desarrollo: peligros y promesas. Washington: BM, 2000.

BRASIL. MCT. Ciência, tecnologia e inovação: desafio para a sociedade brasileira. Livro Verde. Brasília: MCT, Academia Brasileira de Ciências, 2001.

Castiel, Luiz David; SAnz-VAlero, Javier. Entre fetichismo e sobrevivência: o artigo científico é uma mercadoria acadêmica? Cadernos de Saúde Pública, Rio de Janeiro, v. 23, n. 12, p. 3.041-3.050, dez. 2007.

CunHA, Luiz Antônio. Desenvolvimento desigual e combinado no ensino superior: Estado e mercado. Educação e Sociedade, Campinas, v. 25, n. 88, p. 795-817, Especial, out. 2004.

FALBo, Giselle. Considerações sobre o mal-estar na civilização. In: BERNARDEs, Ângela C. (Org.). $10 \times$ Freud. Rio de Janeiro: Azougue; Niterói: Lapso, 2005.

Ferreira, Sérgio T. Para onde vai a ciência brasileira. Ciência Hoje, Rio de Janeiro, v. 42, n. 247, p. 65-67, abr. 2008.

Freud, Sigmund. O mal-estar na civilização [1929/1930]. In: Obras psicológicas completas de Sigmund Freud: edição standard brasileira. Rio de Janeiro: Imago, 2006, v. XXI.

FrigotTo, Gaudêncio. A produtividade da escola improdutiva: um (re)exame das relações entre educação e estrutura econômico-social capitalista. 3. ed. São Paulo: Cortez; Autores Associados, 1989.

. Educação e crise do trabalho: perspectivas de final de século. Petrópolis: Vozes, 1998.

GatTi, Bernadete Angelina. A construção da pesquisa em educação no Brasil. Brasília: Liber Livro, 2007. 
GAY, Peter. Freud: uma vida para o nosso tempo. São Paulo: Cia. das Letras, 1989.

Kuenzer, Acácia Zeneida. Desafios teórico-metodológicos da relação trabalhoeducação e o papel da escola. In: FrigotTo, G. (Org.). Educação e crise do trabalbo: perspectivas de final de século. Petrópolis: Vozes, 1998.

Macedo, Elizabeth; Souza, Clarilza Prado de. A pesquisa em educação no Brasil. Revista Brasileira de Educação. Rio de Janeiro, ANPEd; Campinas, Autores Associados, v. 15, n. 43, p. 166-176, jan./abr. 2010.

Mangas Martín, Araceli. Dispendio universitario en projectos fantasmas. El Mundo em Orbyt. 2 mar. 2010. Disponível em: <http://www.elmundo.es/elmundo/espana.html>. MarX, Karl. Crítica da filosofia do direito de Hegel. São Paulo, Boitempo, 2005.

- O capital: crítica da economia política. Livro I: o processo de produção do capital. Vol. I e II (14. ed.). Rio de Janeiro: Bertrand Brasil, [1890] 1994.

. Capitulo $6^{\circ}$ inédito d'O Capital: resultados do processo de produção imediato. Porto (Portugal): Publicações Escorpião, 1975.

MarX, Karl; Engels, Friedrich. O manifesto comunista. São Paulo: Boitempo, 2002.

Mocelin, Daniel Gustavo. Concorrência e alianças entre pesquisadores: reflexões acerca da expansão de grupos de pesquisa dos anos 1990 aos 2000 no Brasil. Revista Brasileira de Pós-Graduação. Brasília, v. 6, n. 11, p. 35-64, dez. 2009.

Moreira, Antonio Flávio. A cultura da performatividade e a avaliação da pós-graduação em educação no Brasil. Educação em Revista, Belo Horizonte, v. 25, n. 3, p. 23-42, dez. 2009.

Neves, Lúcia Maria Wanderley; Pronko, Marcela Alejandra. O mercado do conhecimento e o conbecimento para mercado: da formação para o trabalho complexo no Brasil contemporâneo. Rio de Janeiro: EPSJV-FIOCRUZ, 2008.

Rodrigues, José. O moderno príncipe industrial: o pensamento pedagógico da Confederação Nacional da Indústria. Campinas: Autores Associados, 1998.

. Os empresários e a educação superior. Campinas: Autores Associados, 2007.

. "Vamos ganhar dinheiro à beça": farsa e tragédia na política do governo Lula para a educação superior. Universidade e Sociedade, Brasília, v. XIX, n. 45, p. 85-92, jan. 2010.

Sguissardi, Valdemar; SiLVA JR., João dos Reis. Trabalbo intensificado nas federais: pósgraduação e produtivismo acadêmico. São Paulo: Xamã, 2009.

VIEIRA, Marcus André. United Symptoms. In: [Site do] XVIII Encontro Brasileiro do Campo Freudiano: O sintoma na clínica do delírio generalizado. 2010. Disponível em: <http://www.ebp.org.br/encontro2010/United_Symptoms.html>. 
Unesco. Educação: um tesouro a descobrir. 10. ed. São Paulo, Cortez; Brasília, MEC-UNESCO, 2006.

\section{SOBRE OS AUTORES}

Eunice Trein é doutora em educação pela Universidade Federal do Rio de Janeiro (UFRJ). Professora associada da Universidade Federal Fluminense (UFF).

E-mail: eunicetrein@ig.com.br

José Rodrigues é doutor em educação pela Universidade Estadual de Campinas (UNICAMP). Professor associado da Universidade Federal Fluminense (UFF).

E-mail:jrodrig@vm.uff.br

Recebido em fevereiro de 2011 Aprovado em abril de 2011 


\section{Approach to plagiarism in the three best universities of each one of the five continents and Brazil}

This study aims to identify different approaches to plagiarism, to compare the approaches of the best universities in the world with Brazilian universities, submit a proposal for coping with plagiarism in Brazil. We conducted a descriptive research document with a non-probability sample drawn from the intentional Webometrics Ranking of World Universities. It was found that the universities in Oceania, Europe and America plagiarism is tackled diverse and comprehensive, involving institutional arrangements, preventive, diagnostic and corrective. It was found that in Brazilian universities, the subject is not approached. Proposes the following actions: institutional performance in the development of academic integrity, definition and dissemination of institutional policy, presentation of content related to plagiarism in the home page of the Brazilian universities, integrating the study of academic writing and plagiarism on the grid of specific courses higher.

Keywords: plagiarism; addressing university; measures of coping.

\section{Planteamiento de plagio en las tres mejores universidades de cada uno de los cinco continentes y de Brasil}

Este estudio tiene como objetivo identificar los diferentes enfoques al plagio, para comparar los enfoques de las mejores universidades del mundo, con universidades de Brasil, presentará una propuesta para hacer frente al plagio en Brasil. Se realizó un documento de investigación descriptiva con una muestra no probabilistica extraídas de la Webometrics Ranking intencional de Universidades del Mundo. Se encontró que las universidades de Oceanía, Europa y América del plagio se aborda diversa y amplia, con inclusión de arreglos institucionales, preventivas, de diagnóstico y correctivo. Se encontró que en las universidades brasileñas, el tema no se aborda. Propone las siguientes acciones: el desempeño institucional en el desarrollo de la integridad académica, definición y difusión de la política institucional, la presentación de los contenidos relacionados con el plagio en la página principal de las universidades brasileñas, integrando el estudio de la escritura académica y el plagio en la parrilla de cursos específicos más alto.

Palabras clave: plagio; enfoque académico; medidas de adaptación.

\section{EUNICE TREIN E JOSÉ RODRIGUES}

\section{O mal-estar na academia: produtivismo científico, o fetichismo do conhecimento-mercadoria}

O ensaio discute o mal-estar provocado pelo fetiche do conhecimento- mercadoria e o seu canto de sereia - produtivismo científico. Na tentativa de explicar 
o mal-estar que impacta a academia, recorremos a Freud para pensar as angústias que nos aprisionam, e a Marx para desvendar as raízes desse mal-estar e sua possível superação. $\mathrm{O}$ texto aponta os limites desse processo e suas consequências pessoais, institucionais e científicas, dialogando com parte da literatura sobre o tema.

Palavras-chave: produtivismo científico; mercantilização do conhecimento; mal-estar na civilização.

The malaise in the academy: scientific productivity, the knowledge-merchandise fetishism

The essay argues the malaise provoked by the knowledge-merchandise fetishism and its mermaid enchantment - scientific productivity. In an attempt to explain the malaise that impacts the academy, we appeal to Freud to think about the anguish that imprison ourselves, and to Marx to reveal the roots of this malaise and its possible overcoming. The text points out the limits of this process and its personal, institutional and scientific consequences, dialoguing with part of literature on the subject.

Keywords: scientific productivity; knowledge commodification; civilization's malaise.

\section{El malestar en la academia: productivismo científico, el fetiche del conocimiento-mercancía}

El texto discute el malestar producido por el fetiche del conocimiento-mercancía nombrado productivismo cientifico. En el intento de explicar el malestar que impacta la academia hemos recurrido a Freud para pensar en la angustia que nos aprisiona y a Marx para comprender las raices del malestar y su posible superación. El texto presenta los limites del proceso y sus consecuencias personales, institucionales y cientificos en diálogo con partes de la literatura sobre el tema.

Palabras clave: productivismo cientifico; mercantilización del conocimiento; malestar en la civilización. 